\title{
Estudo da utilização de fibra de coco em vigas de concreto
}

Este artigo tem por finalidade abordar o estudo da utilização de fibras de coco como reforço de material compósito de cimento, através da avaliação das propriedades mecânicas por meio do ensaio de flexão, consumado no 28 dia da cura, calculando o módulo de ruptura e de elasticidade, e traçando curvas carga $x$ tempo. Neste trabalho, fabricou-se concreto convencional e reforçado com as fibras de coco na dosagem de 1:2: 2,8 com a relação água/cimento de 0,62 em massa e a adição de $1,0 \%$ de fibras de coco. O benefício básico observado na adição das fibras de coco como material de reforço do concreto foi em impedir a ruptura severa dos corpos de prova. Diversas fibras vegetais têm sido empregadas como reforço em materiais compósitos de cimento devido as suas vantagens. A baixa densidade e o bom percentual de alongamento das fibras de coco fazem desta fibra um notável reforço de materiais compósitos.

Palavras-chave: Material compósito; Fibras de coco; Compósitos Reforçados; Fibras.

\section{Study of the use of coconut fiber in concrete beams}

The aim of this paper is to study the use of coconut fibers as reinforcement of cement composite material, by evaluating the mechanical properties through the flexural test, completed on the 28th day of cure, calculating the modulus of rupture and elasticity and plotting load $x$ time curves. In this work, conventional and coconut fiber reinforced concrete was manufactured at a dosage of 1: 2: 2.8 with a water / cement ratio of 0.62 mass and the addition of $1.0 \%$ coconut fiber. The basic benefit observed in adding coconut fibers as a concrete reinforcement material was in preventing severe rupture of specimens. Several plant fibers have been used as reinforcement in cement composite materials due to their advantages. The low density and good elongation percentage of coconut fibers make this fiber a remarkable reinforcement of composite materials.

Keywords: Composite material; Coconut fibers; Reinforced composites; Fibers.

\section{Topic: Engenharia Civil}

Reviewed anonymously in the process of blind peer.
Received: 05/04/2019

Approved: 07/07/2019
Alexandre Moraes Lemos (iD)

Instituto Militar de Engenharia, Brasil

http://lattes.cnpq.br/6371857320606088

http://orcid.org/0000-0002-1788-9059

lemos@ime.eb.br

Flávia Cristina Frendenberg

Universidade Estácio de Sá, Brasil

stefrendenberg@gmail.com

\section{Referencing this:}

LEMOS, A. M.; FRENDENBERG, F. C.. Estudo da utilização de fibra de coco em vigas de concreto. Engineering Sciences, v.7, n.2, p.1-8, 2019. DOI: http://doi.org/10.6008/CBPC2318-3055.2019.002.0001 


\section{INTRODUÇÃO}

O concreto, devido ao seu baixo custo, capacidade de adequação e variação infinita de formas, além da facilidade de confecção e flexibilidade, pode ainda ser produzido no local de aplicação ou processado industrialmente longe do local de aplicação. Bernardi (2003) destaca como sendo o principal material utilizado no mundo pela construção civil. Porém, sem a devida armação, o concreto simples, torna-se quebradiço, frágil, e com baixa resistência e baixa capacidade de alongamento na tração.

A sua composição final gera um grande consumo de energia, sendo recomendável utilizá-lo de forma racional e sustentável. Na tentativa de tornar esse material mais eficaz e resistente, vem aumentando o uso de Concreto reforçado com fibras (CRF) que pode ser definido como um compósito que ser utilizado como uma alternativa ao uso do concreto armado para estruturas contínuas e pré-moldadas (FIGUEIREDO, 2011), e geralmente utilizando cimento Portland, agregados, e fibras descontínuas em sua composição.

O papel das fibras, distribuídas de forma descontínuas e aleatoriamente, é o de transpor as fissuras, que se surgem no concreto, sejam elas ocasionadas por ações de cargas externas ou mudanças de temperatura e umidade. As fibras provocam certa ductilidade após a fissuração. Se as fibras forem suficientemente resistentes, tiverem capacidade de aderência à matriz cimentícia, e em quantidade suficiente, elas auxiliarão na redução da abertura das fissuras.

Permitirão ao CRF resistir a tensões de tração bem elevadas, com uma alta capacidade de deformação no estágio pós-fissuração. Entre as adições utilizadas para aperfeiçoar certas características do concreto, as fibras alcançaram papel de evidência nos últimos anos, sendo objeto de muita pesquisa e desenvolvimento.

As fibras naturais ou sintéticas são empregadas, sobretudo, para minimizar o surgimento das fissuras originadas pela retração plástica do concreto. Esta retração pode ter diversas causas, entre elas, destacamos a temperatura ambiente, o vento e o calor de hidratação do cimento. Seu emprego depende das necessidades de cada obra, mas são utilizadas normalmente em pavimentos rígidos, pisos industriais, projetados, áreas de piscina, pré-moldados, argamassas, tanques e reservatórios, entre outros.

O reforço utilizado no referido trabalho é a fibra do coco, produzida através de processo industrial de prensa e secagem e vendida no mercado em pacotes de 150 gramas. Este material fibroso constitui o mesocarpo do fruto, que além de ser conhecida como fibra, recebe as denominações de 'COIR' e 'BONOTE'. A escolha pela utilização da fibra de coco levou em consideração ser um material do qual já se possui um método de reciclagem, mas que, no entanto, gera muito volume quando se trata de sustentabilidade, pois o resíduo do coco é de difícil degradação e demora mais de oito anos para se decompor completamente (CARRIJO et al., 2002).

Conforme informação do Ministério do Meio Ambiente, um caminho para a solução dos problemas relacionados com o lixo é apontado pelo Princípio dos 3Rs: Reduzir, Reutilizar e Reciclar. Fatores associados a estes princípios devem ser considerados, como o ideal de prevenção e não geração de resíduos, somados à adoção de padrões de consumo sustentável, visando poupar os recursos naturais e conter o desperdício. 
Esta informação traz o embasamento e a inspiração de diversas pesquisas relacionadas ao desenvolvimento de novos materiais aplicados à construção civil.

\section{METODOLOGIA}

Concatenando a busca por um material mais resistente e eficaz, com a problemática apresentada no descarte da casca do coco, o trabalho busca obter um produto seguro, funcional, durável, com menores custos e principalmente sustentável. No ramo da construção civil, as fibras são materiais que já vêm sendo utilizados há muitos anos, porém, a falta de conhecimento no mercado ainda é grande. As fibras de coco possuem características singulares para o combate a certas patologias que degradam as estruturas de concreto em geral.

A utilização de reforços no composto em elementos estruturais é importante para evitar a ruptura brusca e na tentativa de reduzir a área total de fissuras ao longo da peça (CHODOUNSKY et al., 2007). Essas adições de microfibras e macrofibras são uma alternativa para amenizar a aparição destas patologias. (QUININO, 2015). A fissuração em concretos diminui a capacidade de carga do elemento (GAO et al., 2013). Estas aberturas tornam-se vias de acesso para penetração de agentes agressivos, que deterioram principalmente os reforços estruturais metálicos, no caso de sistemas em concreto armado (CARMONA et al., 2006).

\section{Compósitos cimentícios reforçados por fibras}

O compósito é um material multifásico que exibe uma significante proporção das propriedades de ambas as fases dos constituintes, tal que uma melhor combinação de propriedades seja obtida. Muitos compósitos são formados por somente duas fases. Uma delas é a chamada matriz, que é contínua e envolve a outra fase, geralmente chamada de fase dispersiva. As propriedades dos compósitos estão relacionadas com as propriedades das fases constituintes, suas quantidades relativas e geometria da fase dispersiva, (forma e tamanho das partículas), distribuição e orientação (PICANÇO, 2005).

Num compósito reforçado com fibras, a eficiência do reforço pode ser avaliada sob dois critérios principais: priorizando a resistência ou tenacidade dos compósitos em relação à matriz. Esses efeitos dependem do comprimento da fibra, de sua orientação (fibras longas costumam ter uma direção e espaçamento pré-determinados, dentro da matriz, já as fibras curtas, são frequentemente, distribuídas aleatoriamente e normalmente são menores que $50 \mathrm{~mm}$ ) e são muito dependentes do grau de aderência com a matriz.

Quando maior for à aderência, maior a resistência mecânica, porém menor é a tenacidade na fratura. Esse comportamento resulta da possibilidade de aumento da incidência de fraturas das fibras do compósito sob a ação de solicitação mecânica e a consequente diminuição na energia absorvida através do processo de arrancamento da fibra. A dificuldade no tratamento da eficiência da fibra é que parâmetros que ressaltam a resistência à tração não necessariamente conduzem a uma maior tenacidade. 


\section{Matrizes cimentícias}

As matrizes cimentícias são compostas de aglomerantes minerais, podendo conter agregados, que dão origem a concretos, argamassas ou pastas. As matrizes mais utilizadas são aquelas à base de cimento Portland, devido à sua maior resistência mecânica e durabilidade. Num compósito de baixo ou médio desempenho, com fibras de baixo módulo de elasticidade, a matriz, é quem exerce o principal papel de suporte de esforços. Além disso, a matriz deve prover a proteção física e a ancoragem das fibras, transferindo as tensões entre os elementos de reforço. Frequentemente, devido a interações físicas ou químicas, formase, entre as fibras e a matriz uma fase intermediária, chamada interface ou zona de transição que, embora de pequena espessura, pode interferir no controle dos mecanismos de falha, na tenacidade na fratura e na relação tensão deformação do material (DANIEL et al., 1994).

No caso de matrizes cimentícias, o diâmetro das partículas dos agregados torna-se também importante, pois afeta a distribuição das fibras e a quantidade de fibras que pode ser incluída no compósito. O tamanho médio das partículas da pasta de cimento antes da hidratação se encontra entre 10 a $30 \mu$, enquanto se pode considerar que uma argamassa contenha partículas de diâmetro máximo de até cerca de $5 \mathrm{~mm}$. Em concretos nos quais se pretenda inserir fibras, não deveria haver partículas maiores que $20 \mathrm{~mm}$, e preferivelmente, não maiores que $10 \mathrm{~mm}$, pois, do contrário, torna-se difícil obter uma distribuição uniforme das fibras (PICANÇO, 2005).

\section{Durabilidade das matrizes com fibra de coco}

Segundo Jhon et al. (2005), em uma pesquisa observou a durabilidade de matrizes cimentícias com fibra de coco comparando as fibras novas com fibras presentes em uma argamassa utilizada em uma parede construída 12 anos antes. A partir das mostras da parede concluí que a mesma continha um menor teor de unidades lignina do que as fibras novas. Além disso, também foi observado que a amostra da parede externa, exposta a ciclos de umedecimento e secagem, apresentou o menor teor de lignina que a amostra da parede interna, reforçando a ideia de que a lignina teria sido lixiviada.

Podem ocorrer à fragilização da fibra pelo processo de mineralização, resultante da migração de produtos de hidratação, especialmente o hidróxido de cálcio, para a cavidade central, paredes e vazios da fibra, onde cristalizam. Isso pode provocar a ruptura sem alongamento considerável, não contribuindo conforme o esperado para o incremento da tenacidade na matriz cimentícia (TOLEDO FILHO, 1997). A formação de grandes cristais de portlandita (hidróxido de cálcio) pode induzir a decomposição das fibras vegetais, em especial a sua fração de lignina, com a consequente perda de capacidade de reforço nas idades mais avançadas. Isso ocorre em virtude da elevada alcalinidade da água presente nos poros da matriz de cimento Portland (AGOPYAN et al., 2003).

Os autores sugerem algumas soluções para controlar esta degradação que ocorre em virtude do ataque alcalino às fibras: Emprego de matrizes de baixa alcalinidade (cimento com escória de autoforno, por exemplo); Redução da alcalinidade por carbonatação acelerada da matriz; Proteção das fibras com polímeros 
ou agentes bloqueadores da decomposição; Impregnar as fibras com agentes repelentes à água; Impermeabilização da matriz; e Emprego de compósitos em locais permanentemente secos.

\section{Concreto Reforçado com Fibras (CRF)}

O concreto reforçado com fibras (CRF) é um compósito que pode ser utilizado como uma alternativa ao uso do concreto armado para estruturas contínuas e pré-moldados (FIGUEIREDO, 2011). Conforme Figueiredo (2005), o comprimento da fibra deve ser pelo menos duas vezes a dimensão máxima do agregado, sendo usual duas e meia a três vezes para que a fibra possa atuar como ponte de transferência entre tensões nas fissuras, pois a fissura se propaga, em sua maioria, na região de interface entre o agregado graúdo e a pasta de cimento endurecido. Propõe-se a figura 1. Segundo Sperling (2006), as propriedades mecânicas são dependentes de sua estrutura molecular, sendo a energia de ligação e as interações intermoleculares os principais fatores que influenciam sua resistência. A maneira como se produz a fibra também apresenta influência sobre as propriedades da fibra.

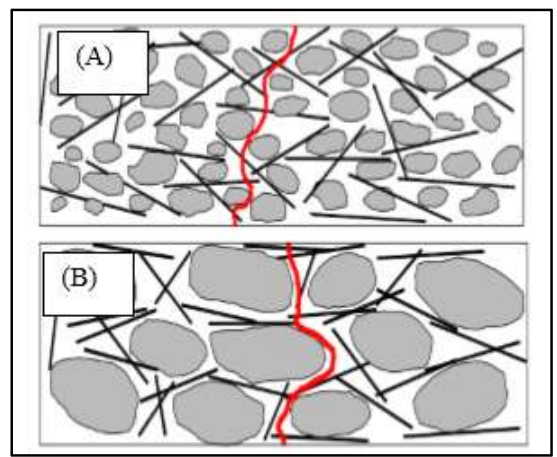

Figura 1: A) Compatibilidade dimensional entre fibra e agregado; e B) Não compatibilidade. Fonte: Figueiredo (2005).

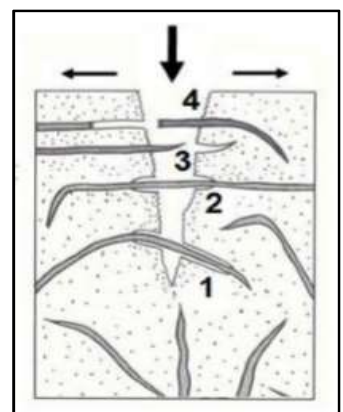

Figura 2: 1) Deslocamento da fibra; 2) Fibra atuando como ponte de transferência entre tensões; 3 ) Arrancamento da fibra; e 4) Ruptura da fibra. Fonte: Tonoli (2009).

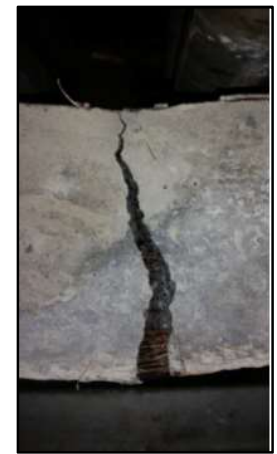

Figura 3: Detalhe da ação da fibra atuando como ponte de transferência de tensões.

\section{RESULTADOS E DISCUSSÃO}

\section{Microscopia Eletrônica de Varredura (MEV)}

Por meio do Microscópio Eletrônico de Varredura (MEV), pode-se constatar na fibra de coco utilizada neste trabalho, a presença de duas fases componentes. A fibra de coco já antes do ensaio de flexão em estado natural, e apresenta-se rugosa, e proporciona adesão com a pasta de cimento durante o processo de secagem. O núcleo é composto por filamentos de fibra no seu interior, que é rígido. Pode-se observar 
também imagens da fibra de coco após a tração sofrida durante o ensaio de flexão, onde ocorre o alongamento dos filamentos.

Para análise no Microscópio Eletrônico de Varredura, a fibra foi revestida com Platina, conforme podemos observar na figura 4, para ter maior condutibilidade. Podemos observar na figura 5, o alongamento da fibra após ser tracionada. Comprovando que a fibra auxiliou na resistência antes de romper. A fibra de coco apresenta uma superfície bastante porosa, a qual facilita a aderência ao concreto. Tal porosidade pode ser observada nas figuras 8 e 9 .

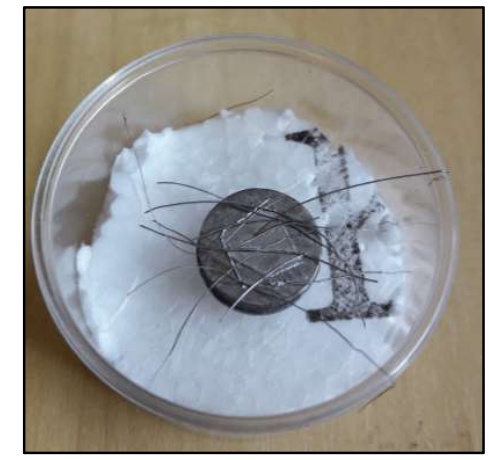

Figura 4: Fibra revestida com Platina.

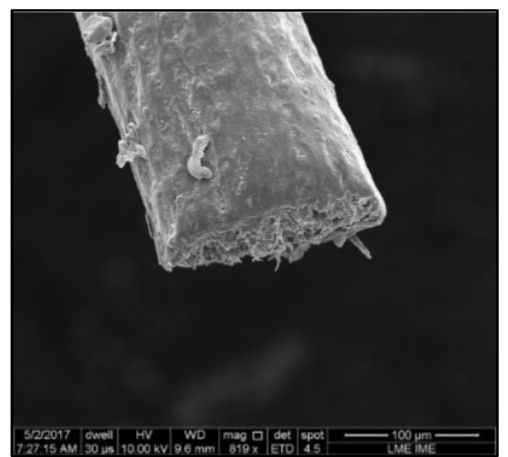

Figura 6: Fibra sem tracionar ampliada 819 vezes.

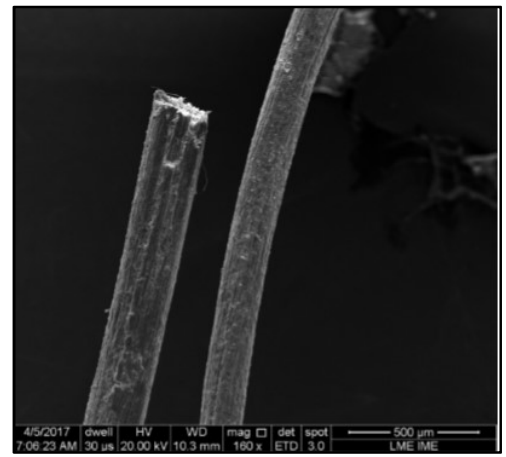

Figura 8: Superfície externa da fibra de coco ampliada 160 vezes.

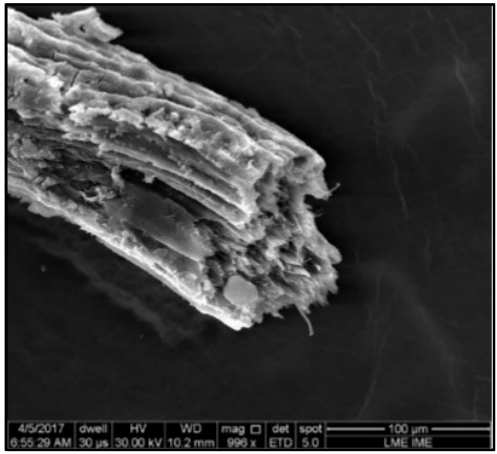

Figura 5: Fibra tracionada ampliada 996 vezes.

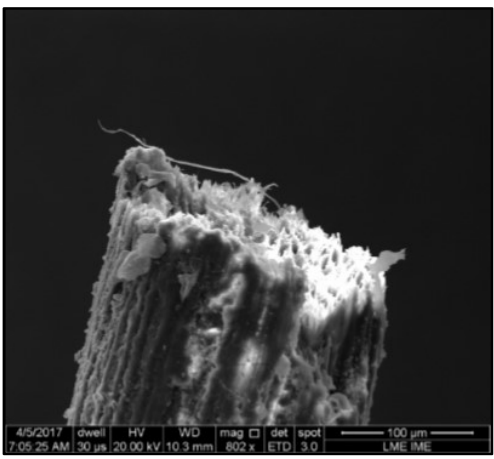

Figura 7: Estrutura interna da fibra de coco ampliada 802 vezes.

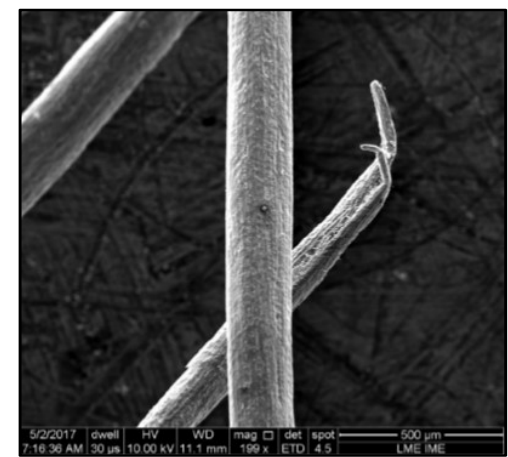

Figura 9: Superfície externa da fibra de coco ampliada 199 vezes.

A fibra vegetal é composta por células individuais, que se aglomeram através da lamela intercelular, que é composta de hemicelulose, pectina e lignina. Na região central da fibra podemos encontrar também, a lacuna, cavidade que juntamente com os lúmens, que fica responsável pelos poros permeáveis nas fibras, acarretando aumento na absorção de água (JÚNIOR, 2000). Nas figuras 10, e 11, podemos observar a estrutura interna da fibra de coco (RAMÍREZ et al., 2010). 


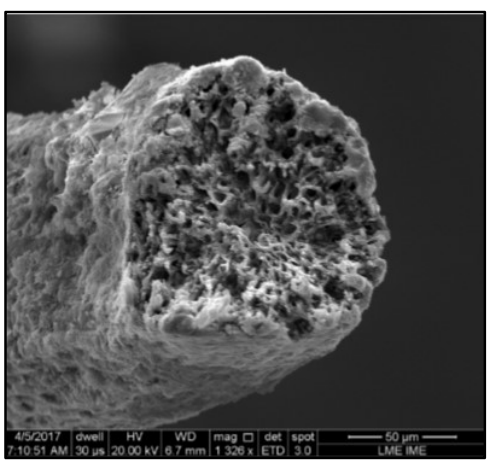

Figura 10: Interior da fibra de coco ampliada 1326 vezes.

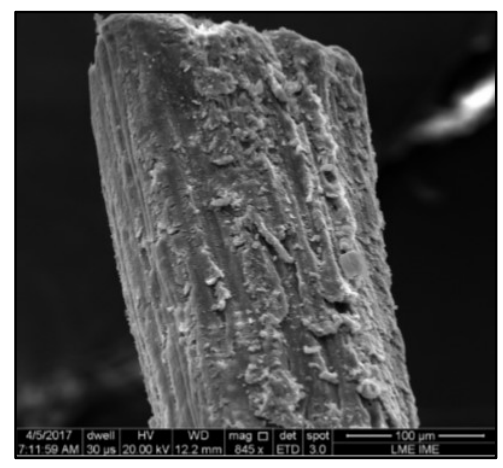

Figura 11: Rugosidade externa da fibra de coco ampliada 845 vezes.

Leão (2012) comparou as propriedades físicas e mecânicas das fibras naturais mais utilizadas como reforço em compósitos de matriz polimérica. a massa específica da fibra de vidro $\left(2,6 \mathrm{~g} / \mathrm{cm}^{3}\right)$ com as das demais fibras vegetais. A massa específica das fibras vegetais é inferior à da fibra de vidro, o que resulta em produtos de baixo peso, dentre as fibras apresentadas, a de coco, destaca-se como a de menor massa específica, junto com Juta.

\section{CONCLUSÕES}

Avaliaram-se as propriedades de concretos com a utilização de fibras de coco como material de reforço de matrizes cimentícias, através da análise das propriedades mecânicas de materiais compósitos, produzidos com concreto reforçados com as fibras de coco. A partir dos resultados, pode-se concluir que a adição de fibras de coco no concreto levou à diminuição das suas propriedades mecânicas, independentemente do comprimento das fibras.

O concreto com fibras de coco, comparadas com a convencional, sustentou a tensão até mesmo após a ruptura, podendo assim, ser benéfica em termos de segurança, evitando que o material se rompa bruscamente. Além disso, ainda temos o benefício na questão ambiental. Enquanto o concreto com as fibras de coco possui tais benefícios diante da convencional, para as propriedades mecânicas foram obtidos valores reduzidos comparados ao concreto convencional e do concreto com fibras de coco.

\section{REFERÊNCIAS}

AGOPYAN, V.; SAVASTANO JUNIOR, H.. Fibras vegetais como materiais de construção. In: ISAIA, G. C.. Materiais de construção civil e princípios de ciência e engenharia de materiais. São Paulo: Ibracon, 2007.

BERNARDI, S. T.. Avaliação do comportamento de materiais compósitos de matrizes cimentícias reforçadas com fibra de Aramida Kevlar. Dissertação (Mestrado em Engenharia) Universidade Federal do Rio Grande do Sul, Porto Alegre, 2003.

CARMONA, T. G.; HELENE, P.. Modelos de previsão da despassivação das armaduras em estruturas de concreto sujeitas à carbonatação. São Paulo: Universidade de São Paulo, 2006.
CARRIJO, O. A.; LIZ, R. S.; MAKISHIMA, N.. Fibra da casca do coco verde como substrato agrícola. Horticultura Brasileira, Brasília, v.20, n.4, p.533-535, 2002.

CHODOUNSKY, M. A.; VIECILI, F. A.. Pisos industriais de concreto: aspectos teóricos e executivos. São Paulo: Reggenza, 2007.

DANIEL, I. M.; ISHAI, O.. Engineering Mechanics of Composite Material. New York: Oxford University Press, 1994.

FIGUEIREDO, A. D.. Concreto com fibras. Ensino, Pesquisa e Realizações, v.2, p.1195-1225, 2005.

GAO, Y.; ZHANG, J.; HAN, P.. Determination of stress relaxation parameters of concrete in tensions at early-age by 
ring test. Construction and Building Materials, v.41, p.152164, 2013.

JHON, V. M.; CINCOTTO, M. A.; SJOSTROM, C.; AGOPYAN, V.; OLIVEIRA, C. T. A.. Durability of slag mortar reinforced with coconut fibre. Cement \& Concrete Composites, v.27, p.565574, 2005.

JÚNIOR, H. S.. Materiais à base de cimento reforçados com fibra vegetal: reciclagem de resíduos para construção de baixo custo. Tese (Doutorado) - Escola Politécnica, Universidade de São Paulo, 2000.

LEÃO, R. M.. Tratamento superficial de fibra de coco e aplicação em materiais compósitos como reforço do polipropileno. Tese (Doutorado) - Universidade de Brasília, Brasília, 2012.

\section{PICANÇO, M. S.. Compósitos cimentícios reforçados com} fibras curauá. Dissertação (Mestrado em Engenharia Civil) Pontifícia Universidade Católica do Rio de Janeiro, Rio de Janeiro, 2005.
QUININO, U. C. M.. Investigação experimental das propriedades mecânicas de compósitos de concreto com adições híbridas de fibras. Tese (Doutorado em Engenharia Civil) - Universidade Federal do Rio Grande do Sul, Porto Alegre, 2015.

RAMÍREZ, M. G. L.; MUNIZ, G. I. B.; SATYANARAYANA, K. G.; TANOBE, V.; IWAKIRI, S.. Preparation and characterization of biodegradable composites based on Brazilian cassava starch, corn starch and green coconut fibers. Matéria, v.15, n.2, p.330-337, 2010.

SPERLING, L. H.. Introduction to phisycal polymer science. 4 ed. Hoboken: John Wiley \& Sons, 2006.

TOLEDO FILHO, R. D.. Materiais compósitos reforçados com fibras naturais: caracterização experimental. Tese (Doutorado) - Pontifícia Universidade Católica do Rio de Janeiro, Rio de Janeiro, 1997.

A CBPC - Companhia Brasileira de Produção Científica (CNPJ: 11.221.422/0001-03) detém os direitos materiais desta publicação. Os direitos referem-se à publicação do trabalho em qualquer parte do mundo, incluindo os direitos às renovações, expansões e disseminações da contribuição, bem como outros direitos subsidiários. Todos os trabalhos publicados eletronicamente poderão posteriormente ser publicados em coletâneas impressas sob coordenação da Sustenere Publishing, da Companhia Brasileira de Produção Científica e seus parceiros autorizados. Os (as) autores (as) preservam os direitos autorais, mas não têm permissão para a publicação da contribuição em outro meio, impresso ou digital, em português ou em tradução. 